\title{
Cost-effectiveness of the PDSAFE personalised physiotherapy intervention for fall prevention in Parkinson's: an economic evaluation alongside a randomised controlled trial
}

Yiqiao Xin ${ }^{1}$, Ann Ashburn², Ruth M. Pickering ${ }^{3}$, Kim Chivers Seymour ${ }^{2}$, Sophia Hulbert ${ }^{2}$, Carolyn Fitton², Dorit Kunkel ${ }^{2}$, loana Marian ${ }^{3}$, Helen C. Roberts ${ }^{3}$, Sarah E. Lamb ${ }^{4}$, Victoria A. Goodwin ${ }^{5}$, Lynn Rochester ${ }^{6}$, Emma Mclntosh $^{{ }^{*}}$ and on behalf of the PDSAFE Collaborative group

\begin{abstract}
Background: PDSAFE is an individually-tailored, physiotherapist-delivered, balance, strength and strategy training programme aimed at preventing falls among people with Parkinson's. We evaluated the cost-effectiveness of PDSAFE compared with usual care for people with Parkinson's at higher risk of falling, from a UK National Health Service and Personal Social Service perspective.

Methods: Resource use and quality of life data (EQ-5D-3L) were collected from 238 participants randomised to the PDSAFE intervention and 236 participants randomised to control, at baseline, 3 months, 6 months (primary outcome), and 12 months. Adjusted cost and quality-adjusted life-years (QALYs) were estimated using generalised linear models and uncertainty estimated using a non-parametric bootstrap.

Results: Over 6 months, the PDSAFE intervention was associated with an incremental cost of $£ 925$ (95\% Cl £428 to $£ 1422)$ and a very small and statistically insignificant QALY gain of $0.008(95 \% \mathrm{Cl}-0.006$ to 0.021$)$. The resulting incremental cost-effectiveness ratio (ICER) was $£ 120,659$ per QALY and the probability of the intervention being cost-effective at a UK threshold of $£ 30,000 /$ ALY was less than $1 \%$. The ICER varied substantially across subgroups although no subgroup had an ICER lower than the $£ 30,000$ threshold. The result was sensitive to the time horizon with the ICER reducing to $£ 55,176$ per QALY when adopting a 12-month time horizon and assuming a sustained treatment effect on QoL, nevertheless, the intervention was still not cost-effective according to the current UK threshold.

\footnotetext{
* Correspondence: Emma.Mclntosh@glasgow.ac.uk

${ }^{1}$ Health Economics and Health Technology Assessment (HEHTA), Institute of Health \& Wellbeing, University of Glasgow, 1 Lilybank gardens, Glasgow G12 $8 R Z, U K$

Full list of author information is available at the end of the article
}

(c) The Author(s). 2020 Open Access This article is licensed under a Creative Commons Attribution 4.0 International License, which permits use, sharing, adaptation, distribution and reproduction in any medium or format, as long as you give appropriate credit to the original author(s) and the source, provide a link to the Creative Commons licence, and indicate if changes were made. The images or other third party material in this article are included in the article's Creative Commons licence, unless indicated otherwise in a credit line to the material. If material is not included in the article's Creative Commons licence and your intended use is not permitted by statutory regulation or exceeds the permitted use, you will need to obtain permission directly from the copyright holder. To view a copy of this licence, visit http://creativecommons.org/licenses/by/4.0/ The Creative Commons Public Domain Dedication waiver (http://creativecommons.org/publicdomain/zero/1.0/) applies to the data made available in this article, unless otherwise stated in a credit line to the data. 


\begin{abstract}
(Continued from previous page)
Conclusions: Evidence from this trial suggests that the PDSAFE intervention is unlikely to be cost-effective at 6 months. The 12-month analysis suggested that the intervention became closer to being cost-effective if quality of life effects were sustained beyond the intervention period, however this would require confirmation. Further research, including qualitative studies, should be conducted to better understand the treatment effect of physiotherapy and its impact on quality of life in people with Parkinson's given existing mixed evidence on this topic.
\end{abstract}

Trial registration: ISRCTN48152791. Registered 17 April 2014. http://www.isrctn.com/ISRCTN48152791

Keywords: Parkinson's, Physiotherapist, Cost-effectiveness, Quality of life, Cost

\section{Background}

Improving balance and reducing falls are identified as the leading priority of the James Lind Alliance [1] top 10 priorities for people with Parkinson's [2]. People with Parkinson's are twice as likely to fall as healthy older people; a recent US study revealed that the overall falls incidence rate ratio comparing people with Parkinson's versus non-Parkinson's subjects was 2.05 (95\% confidence interval (CI) 1.88-2.24), adjusting for comorbidity and medications [3]. Falling can have serious health and quality of life consequences such as fractures, $[4,5]$ immobility and fear of falling [6] leading to dependency and social isolation [7]. Falling also increases the psychological burden on informal caregivers, increases personal costs (e.g. home alteration), [8] as well as costs to the health care system. A recently published (2018) 10-year UK cohort study analysed linked health care data from 7060 people with Parkinson's, and the cost of inpatient care was found to be $£ 900$ per year greater compared to age and sex matched controls [9]. Among the reasons for admission to inpatient care (e.g. infection, dementia etc.), falls and related fractures were most frequently cited, accounting for $13 \%$ of the total cases [10]. In Germany, direct costs among the people with Parkinson's who experienced falls was considerably higher than among people with Parkinson's who did not fall ( $€ 3180$ and $€ 1300$ respectively) due to the longer duration of hospitalisation [11].

Frequent and repeated falls are not prevented with medication, [12] however, several studies have shown that physiotherapy can be beneficial through exercise, strength and balance training, [13-15] yet it is unclear whether physiotherapy reduces the rate of falling [16, 17]. A UK multi-centre, single blind, randomised controlled trial, was conducted to evaluate the effectiveness and cost-effectiveness of a novel, home-based physiotherapy programme, PDSAFE, compared to usual care for falls management in people with Parkinson's [18].

Economic evaluation alongside clinical trials compares the cost and outcomes of health care interventions implemented in the randomised arm of the trial and makes recommendations to decision makers regarding intervention cost-effectiveness. The objective of this study was to estimate the cost-effectiveness of the PDSAFE intervention compared to usual care in people with Parkinson's who had a history of falling.

\section{Methods}

Trial eligibility criteria, baseline characteristics, intervention, and outcome measures

Between 2014 and 2016, 474 participants were randomised to receive the PDSAFE intervention $(n=238)$ or usual care $(n=236)$ for a six-month period. Patients were eligible if they: had a confirmed consultant's diagnosis of Parkinson's; were independently mobile; experienced $\geq 1$ fall in the previous 12 months; scored $\geq 24$ on Mini-Mental State Examination [19]; and were able to give informed consent, understand and follow commands, and complete a guided personalised exercise and strategy programme. These participants were on average aged 71 (SD 7.7) and 73 (SD 7.7) in the intervention and control group, with a mean of 8 (SD 6.6) and 8 (SD 5.8) years of diagnosis of Parkinson's respectively, a median Hoehn \& Yahr scale stage of 3 in both groups, and a mean Movement Disorder Unified Parkinson's Disease Rating Scale (UPDRS) score of 32 (SD 15.2) and 33 (SD 17.3) respectively [18]. The proportion of participants that had freezing of gait in the past month prior to randomisation was $64 \%$ in the intervention group and $59 \%$ in the control group. Both of the groups had a median of 3 falls in the 12 months prior to screening, and $78 \%$ in the intervention group and $80 \%$ in the control group had repeat falling during the same period [18]. In the 3 months prior to randomisation, the intervention and control participants had a median of 2 and 1 fall respectively [18]. The trial protocol, including a summary of economic evaluation methods, and the detailed trial primary outcome results are published elsewhere [14, 18, 20].

The PDSAFE programme was personalised to each participant by a physiotherapist through a clinical assessment and targeted specific problems in their home environment. Exercises and strategies were selected from a menu of activities and provided to participants in a booklet accompanied by video vignettes on a DVD. Each participant was provided up to 12 one-hour sessions. Participants in the control group received usual care 
plus a DVD on Parkinson's and one advice session after trial completion. All participants were assumed on appropriate doses of medications during the trial following specialist Parkinson's services. The primary outcome was the risk of repeat falling during the 6 months post randomisation.

\section{Overview of economic evaluation methods}

A 'within-trial' 6-month cost-utility analysis was conducted from the perspective of UK National Health Service (NHS) and Personal Social Service (PSS) under the principle of intention-to-treat, following recommendations for good practice [21, 22]. Costs included intervention costs and NHS and social care cost. Resource use, and QoL measured using the EQ-5D-3L instrument [23] were collected at baseline, 3 and 6 months. Missing data were imputed using multiple imputation methods [24]. The incremental cost-effectiveness ratio (ICER) was compared with a $£ 20,000-£ 30,000$ per QALY threshold currently applied by UK's NICE [21]. Subgroup and sensitivity analyses in relation to cost reduction strategies and longer follow-up period up to 12 months were conducted. A non-parametric bootstrap with 1000 iterations was conducted to explore the uncertainty around the ICER estimate. All analyses were undertaken in STATA/ SE 12.0 [24]. Details of methods were previously published elsewhere [25].

\section{Routine resource use}

Questionnaires were posted to participants to collect NHS and social care resource use data. These included: i) primary care services (GP visits, routine physiotherapy, etc.), ii) secondary care services (ambulance, hospitalisation, etc.), iii) social care services (home care visits, meals on wheels, etc.), and iv) medication use. Medication was not included in the total costs given the low possibility that the intervention would impact on the consumption of medication, as well as the large number of low-cost medications reported. Unit costs were sourced from the Personal Social Service Research Unit (PSSRU) [26] and the NHS National Schedule of Reference Costs [27] for a base financial year 2016 (Supplementary material 1).

\section{Cost of personalised home-based physiotherapy}

The cost of therapy sessions included physiotherapists' salaries, training, travel, equipment and consumables. Physiotherapists' salaries were estimated based on the UK NHS band six full-time equivalent. Physiotherapists received 2 days of training, costed as the time spent by the trainer (lead physiotherapist), room hire and training materials. Equipment included printed materials and DVDs of the intervention demonstration provided to each participant in the intervention group, and a variety of assisted equipment provided to a proportion of participants as needed, including weighted vests, balance pads, and steps. All equipment was retained by the physiotherapists and used across participants. Costs associated with the equipment were annualised with a discount rate of 3.5\% [21] over the anticipated life span where appropriate.

\section{Quality of Life (QOL) and Quality Adjusted Life Years (QALYs)}

QoL was measured using the EQ-5D-3L [28] instrument and utility scores were generated using tariff values previously elicited from a UK general population sample [29]. The area-under-the-curve approach was used to estimate QALYs where the change between the two assessment points was assumed to be linear [30]. Participants who died had their utility score and resource use set to zero from the next assessment point after death.

\section{Missing data and multiple imputation}

Missing cost or EQ-5D-3L utility values were imputed using multiple imputation with chained equations and the predictive mean matching method was used [24]. The imputation was conducted separately within the PDSAFE and control groups. 50 imputed datasets were created. EQ-5D-3L was imputed at the utility value level (rather than at the dimension level), and cost items were imputed as categories (NHS cost excluding hospitalisation, hospitalisation cost, and social care cost) following recommended practice [24]. Missingness at item level was imputed with zero assuming no resource was used if any other item within the same cost categories was completed in the questionnaire. Given the relatively high cost of hospitalisation, any missing data in hospitalisation were cross checked with falls diaries before imputation for accuracy purposes.

\section{Statistical analysis}

Adjusted differences in costs and QALYs between the randomised groups were estimated using generalised linear models. Cost and QALYs were estimated using a Gamma distribution and a normal distribution respectively. Baseline utility scores and costs were adjusted. Other covariates adjusted were selected based on statistical significance in a regression predicting the likelihood of missingness from the full list of demographics, medical history, and screening measures. The resulted list of covariates included: age, gender, Hoehn \& Yahr scale, [31] Montreal Cognitive assessment score, [32] MiniMental State Examination score, [19] presence of diabetes, history of myocardial infarction, history of ischemic heart disease, history of deep brain stimulation and presence of an informal carer. 
The method of recycled predictions was used to estimate mean costs and QALYs of each trial arm. The ICER was estimated by dividing the adjusted cost difference between the randomised groups by the adjusted QALY difference. Uncertainty in the ICER estimate was evaluated using a 1000-iteration bootstrap and the probabilities that the intervention was cost-effective under a wide range of hypothetical thresholds $(£ 0-£ 200,000)$ were presented in the cost- effectiveness acceptability curve.

\section{Sensitivity analysis}

A variety of sensitivity analyses were conducted to assess the impact on the cost-effectiveness results. First, an alternative 12-month time horizon analysis was undertaken. In part due to funding cessation, 12-month follow-up data were only available for approximately half of the participants, and cost, outcome and covariate data were imputed for the participants who were not followed up to 12 months. Second, the number of therapy sessions was reduced from the 12 sessions in the base case as implemented in the trial to alternatives of 10 sessions and 8 sessions over a six-month period assuming maintained QoL, to explore the impact of lowering the intervention costs on the cost-effectiveness result. Next, complete case analysis was implemented assuming data were missing completely at random to assess the impact of missing data on the cost-effectiveness results. Lastly, the number of routine NHS physiotherapist visits was excluded from the total cost addressing the possibility that participants could not differentiate between an NHS or trial physiotherapist when answering the questionnaire.

\section{Subgroup analysis}

Effectiveness of the intervention was differential in four subgroups [18] and therefore cost-effectiveness analyses were conducted in subgroups defined by these four criteria. They are: UPDRS scores, Montreal Cognitive assessment cognitive function scores, presence of freezing symptoms measured by a standardised Freezing of gait questionnaire [33], and number of retrospective falls. The incremental effects across the groups were generated using recycled prediction methods to balance the covariates.

\section{Results}

\section{Intervention cost}

The total cost of the PDSAFE intervention was $£ 650$ per participant in the intervention arm (Table 1). The cost of physiotherapists' time and travel expenses accounted for over $95 \%$ of the total intervention cost.

\section{Resource use and costs}

Over the 6-month period, participants in the intervention group had fewer GP, practice nurse or home care help visits, though none of the differences was statistically significant (Supplementary material 2). The most frequently used social service was home care: on average

Table 1 PDSAFE intervention costs

\begin{tabular}{|c|c|c|c|}
\hline Item & Unit cost $(£)$ & Quantity & Sum $(£)$ \\
\hline \multicolumn{4}{|l|}{ Therapists training } \\
\hline Trainer (lead therapist) & 165 per day & 1.75 days & 288.75 \\
\hline Room hire & 150 per day & 2 days & 300 \\
\hline Training materials & 3.50 per therapist & 14 therapists & 49 \\
\hline \multicolumn{4}{|l|}{ Therapy sessions } \\
\hline Therapist time & 43.62 per visit & 238 participants * 12 & $124,578.72$ \\
\hline Consumables (clinical notes) & 1.20 per visit & 238 participants * 12 & 3427.20 \\
\hline Travel expenses & 8 per visit & 238 participants * 12 & 22,848 \\
\hline \multicolumn{4}{|c|}{ Patient equipment during the sessions } \\
\hline Printed materials & 2 per participant & 238 participants & 476 \\
\hline CDs & 0.08 per participant & 238 participants & 19.04 \\
\hline Weighted vests & 54.16 each & $23.8^{\mathrm{a}}$ & 1289.01 \\
\hline Balance pads & 19.41 each & $59.5^{\mathrm{b}}$ & 1154.90 \\
\hline Step counts & $\begin{array}{l}11.99 \text { each } \\
\left(6.31^{\circ}\right)\end{array}$ & $15.87^{d}$ & 100.14 \\
\hline Total cost (per patient $n=238)$ & 649.60 & & \\
\hline
\end{tabular}

Note: a. Approximately 1 in 5 participants used a weighted vest. Each weighted vest was used for two participants for all visits. $(238 / 5) / 2=23.8$

b. Approximately 1 in 2 participants used a balance pad. Each pad was used for two participants for all visits. $(238 / 2) / 2=59.5$

c. Annualised cost over 2 years: $\mathrm{K} /\left[\left(1-(1+\mathrm{r})^{-\mathrm{n}}\right) / \mathrm{r}\right]$. $\mathrm{K}=11.99, \mathrm{r}=3.5 \%, n=2$

d. Approximately 1 in 15 participants used a step count: $238 / 15=15.87$ 
each participant in the intervention group had 13 visits compared to 30 visits in the control group. Overall, there was no statistically significant difference in the cost of resource use between the groups. The total 6-month cost of service use per patient was $£ 3137$ (95\%CI $£ 2602$, $£ 3673$ ) in the intervention group and $£ 3069$ (95\% £2621, $£ 3518)$ in the control group, with a non-statistically significant difference of $£ 68$ (95\%CI - $£ 634, £ 770)$.

\section{QoL and QALYs}

The completeness of EQ-5D-3L questionnaire at the month 6 follow-up was 79\% (188/238) and 90\% (213/ 236) for the intervention and control groups respectively. The utility values of the intervention group declined slightly less than the control group in the 6month and 12-month periods (Fig. 1). The differences in utility values between the groups were small ( 0.031 at 6 months, and 0.017 at 12 months), and not statistically significant.

\section{Cost-effectiveness base-case analysis}

The adjusted costs of the intervention and control group were $£ 4020$ (95\%CI £3531, £4510) and £3095 (95\%CI $£ 2694$, £3496) respectively, leading to an incremental cost of $£ 925$ (95\%CI $£ 428, £ 1422$ ). The adjusted QALYs of the intervention and control group were $0.336(95 \% \mathrm{CI}$ $0.326,0.345)$ and $0.328(95 \% \mathrm{CI} 0.319,0.337)$ respectively, which resulted an incremental QALY of $0.008(95 \% \mathrm{CI}$ $-0.006,0.021)$. The resulting ICER was $£ 120,659$ per QALY gained. All the bootstrapped cost-utility pairs (Fig. 2a) were in the northern quadrants, indicating that the cost consumed in the intervention group was always greater than in the control group. Similarly, the majority of the simulated cost-utility dyads were in the north-east quadrant, indicating that the intervention was more likely to improve mean health outcomes than the control group. The cost-effectiveness plane crossing the y axis indicates that there was a higher degree of uncertainty surrounding the estimate of the incremental QALY than the estimate of incremental cost, leading to a wide $95 \%$ confidence interval for the estimate of ICER. The costeffectiveness acceptability curve (Fig. 2b) shows that the probability that the intervention was cost-effective at the $£ 30,000$ threshold was $0.5 \%$.

\section{Subgroup and sensitivity analysis}

The ICER was above £30,000 for all subgroups indicating the intervention was not cost-effective in any

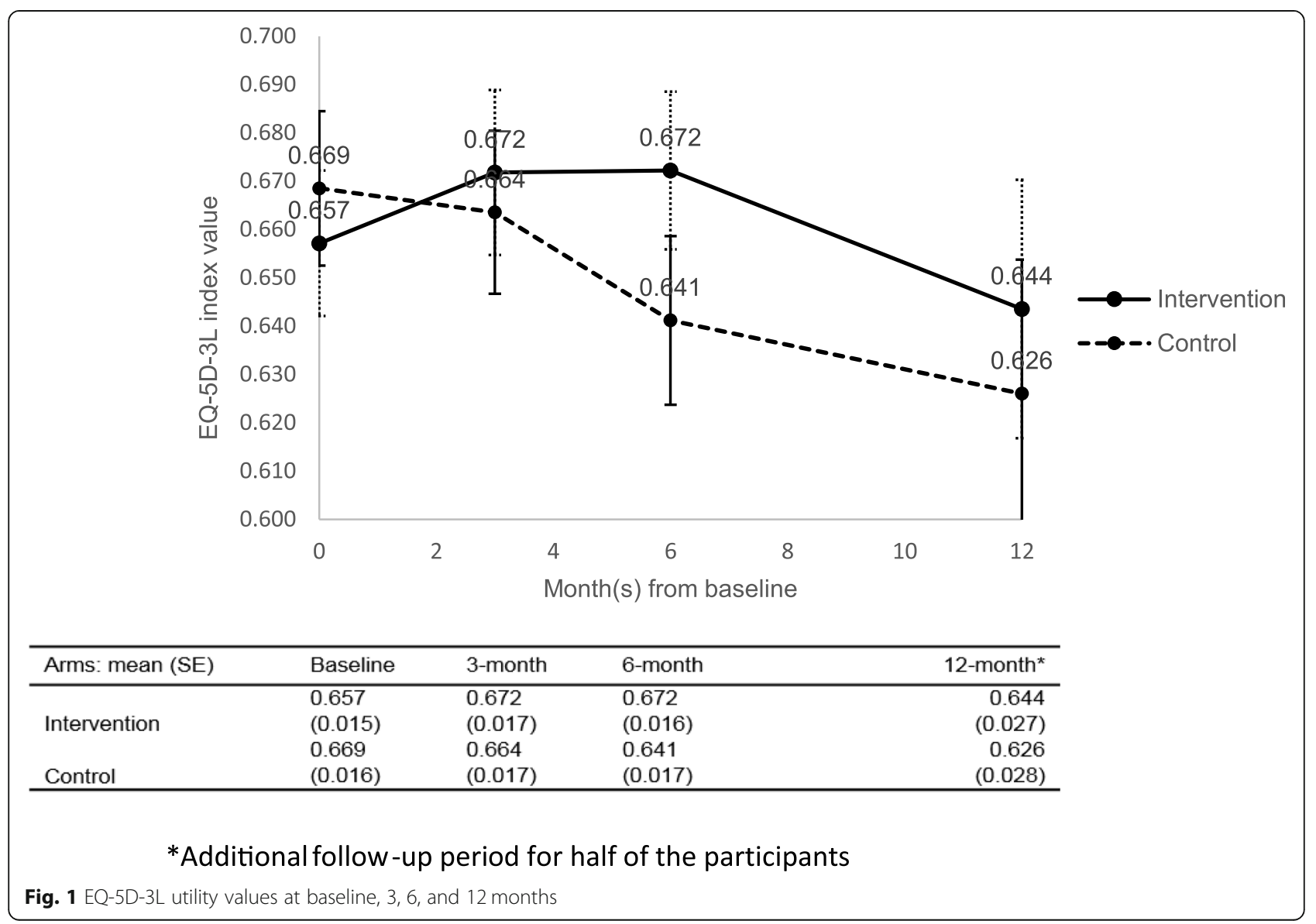




\section{a. Cost-effectiveness plane}

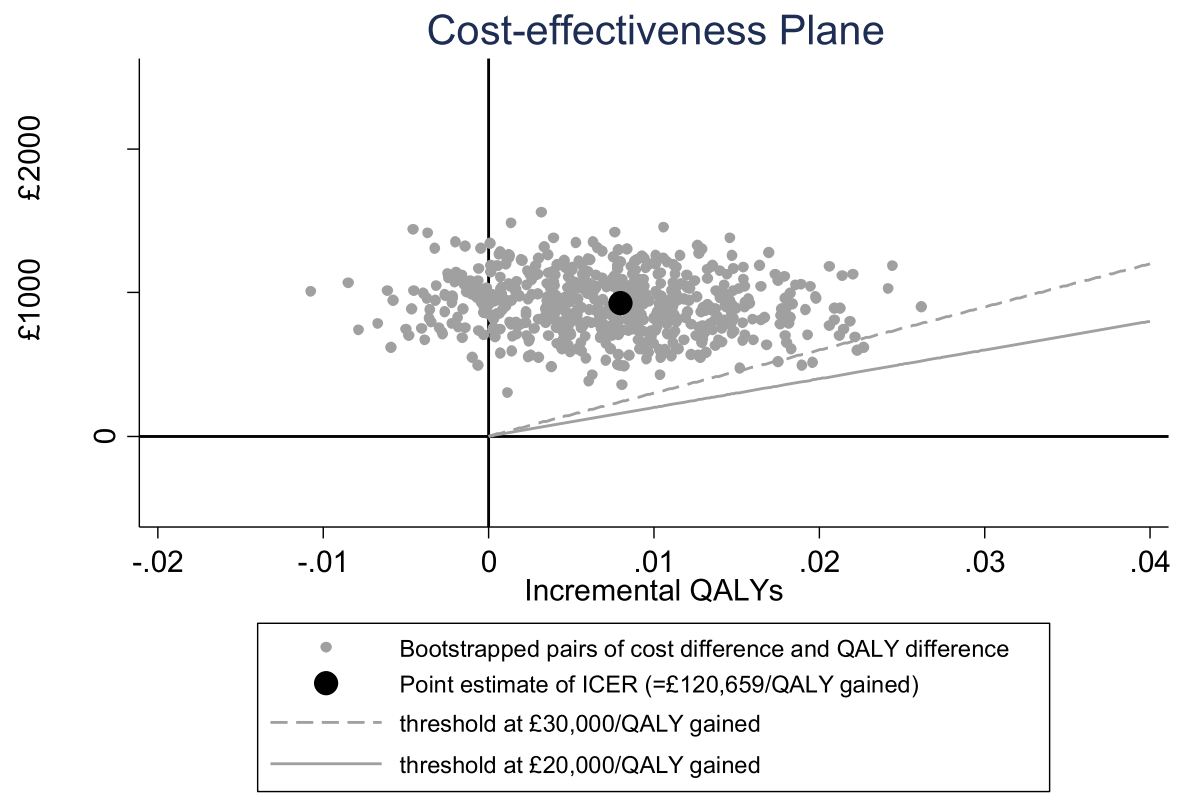

\section{b. Cost-effectiveness acceptability curve}

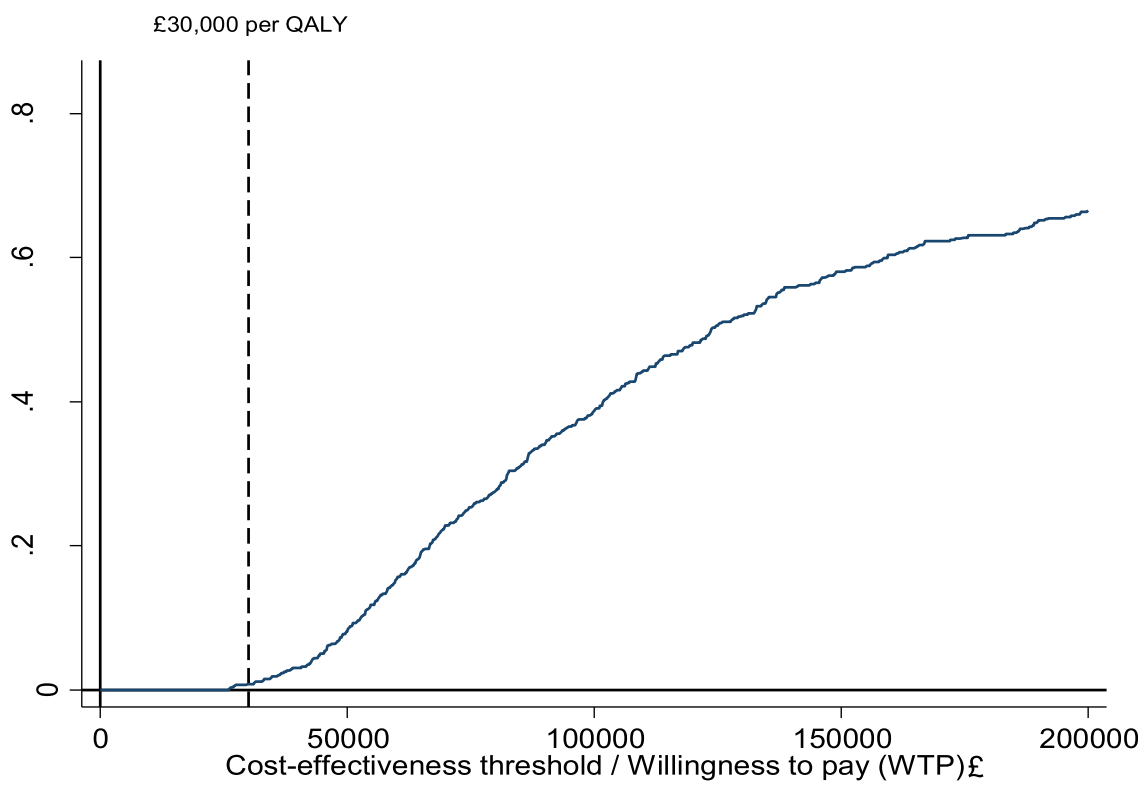

Fig. 2 Cost-effectiveness plane (a) and cost-effectiveness acceptability curve (b) of the PDSAFE intervention vs. usual care

subgroup (Supplementary material Table 3a). The incremental QALYs in the intervention arm for those who had not experienced freezing episodes was statistically significantly greater $(0.021,95 \%$ CI 0.0007 , $0.041)$, although the ICER remained high $(=£ 61,687$ per QALY). In the sensitivity analyses, while the PDSAFE intervention was still not cost-effective compared to the control arm in all scenarios, the ICER decreased by more than half when estimated over a 12-month time horizon (Supplementary material Table 3b).

\section{Discussion}

The results showed that the PDSAFE intervention was unlikely to be cost-effective from an NHS and PSS's perspective over the trial horizon. There was minimal difference between arms in the total cost of NHS and 
social service use. The utility values in the intervention group declined slightly less than the control group over the trial period, but the difference was minimal and not statistically significant.

A high degree of uncertainty over the QALYs gained led to a wide confidence interval in the ICER, which may be due to the small mean QALY gained and large variation among the participants. This may also be related to the limitation of the EQ-5D-3L instrument [34] in capturing the impact of the PDSAFE intervention on QoL aspects such as improved falls efficacy and less fear of falling as identified in the effectiveness results and a qualitative investigation as part of the PDSAFE trial [25].

Sensitivity analyses indicated that the intervention was more likely to be cost-effective if a 12-month time horizon was adopted. If the difference lasts beyond the 12-month follow-up point, the probability of the intervention being cost-effective would be expected to increase because the cost of intervention would be recouped over a longer time horizon and incremental QALY gain would be larger, however further research would be needed to fully examine this. Exploratory analysis of the observed 6 month data found the treatment effect to be greater among the participants who did not provide 12-month data compared to those who did. This suggests that if those participants were followed up to 12 months, a potentially greater treatment effect at 12 months might have emerged. This may also suggest that the participants who received the intervention later may gain more benefit than the participants who received the intervention early, possibly due to the learning curve of the trial physiotherapists, however these could all be due to chance.

Several studies have evaluated the cost-effectiveness of exercise programmes or physiotherapy programmes previously and the results were mixed. Clarke et al. (2016) evaluated effectiveness and cost-effectiveness of physiotherapy and occupational therapy versus no therapy in the PD REHAB randomised controlled trial among 762 patients with mild to moderate Parkinson's disease [35]. They found that individualised physiotherapy and occupational therapy did not have immediate (3 months) or long-term (15 months) clinically meaningful improvements in activities of daily living or QoL measured by PDQ-39. Although no difference in primary outcome was found, the ICER was only $£ 3493 / \mathrm{QALY}$ ( $-£ 169,371$ to $£ 176,358)$ with $50.5 \%$ probability to be under the $£ 20,000$ threshold. The authors, noting the wide confidence interval surrounding the ICER as well as the insignificant QALY gain, concluded that the cost-effectiveness result was contingent on a clinically meaningful primary outcome which had not been found. An earlier trial (2012) by Fletcher et al. reported a more positive result in favour of a 10-week exercise programme with 0.03 (-0.02 to 0.08$)$ incremental
QALY gained and $£ 35$ less health and social care costs, which suggested the intervention was dominant with approximately $80 \%$ probability that the intervention was cost-effective [36]. The intervention cost $£ 76$ per participant for the complete 10-week group sessions in community settings in this trial. Notably, the cost-effectiveness analysis alongside this trial incorporated only 93 of the 130 participants who were randomised, and there was no imputation strategy for missing data hence these results could be subject to selection bias. An Australian study evaluated the cost-effectiveness of a similar exercise intervention led by a physical therapist (a mixture of group and individual sessions) among Parkinson's population and estimated the cost to be \$A574 per fall averted and a ICER of $\$ A 338,800 / \mathrm{QALY}$ with a 0.005 QALY gain over a 6month period [37]. The intervention cost was estimated to be \$A1,010 (in 2012 Australian dollars, equivalent to £559) per participant which incorporated monthly group exercise classes, and 2 to 4 home visits from the therapist over 6 months. They concluded that the intervention was cost-effective when using a threshold of $\$ A 2,000$ per fall prevented however the ICER estimate was far over the UK equivalent threshold $£ 20,000$ to $£ 30,000$ per QALY gained. Compared to the current study, both Clarke et al. and Fletcher et al. $[35,36]$ reported much more positive costeffectiveness estimates favouring the intervention, due to the lower intervention costs and higher QALYs gained. The result from the Australian study is consistent with the current study, reporting similar intervention cost ( $£ 559$, vs. $£ 649$ for PDSAFE) and similar QALY (0.005 vs. 0.008 for PDSAFE) gained. Overall the QALY gained in the three earlier studies and the PDSAFE trial were small and measured with substantial uncertainty. Further studies should be conducted to better understand the treatment effect of physiotherapy and its impact on QALY.

\section{Conclusions}

Over the 6-month period, the PDSAFE intervention was associated with a small, statistically insignificant mean QALY gain with large uncertainty, leading to a large ICER with a wide confidence interval. The uncertainty analysis revealed that the probability of the intervention being cost-effective was $0.5 \%$ suggesting that the PDSAFE intervention is unlikely to be cost-effective from the NHS and PSS perspective. Sensitivity analysis showed that even if the number of PDSAFE physiotherapy sessions were reduced from 12 to 8 , the ICER would still be three times higher than the current NICE threshold due to the unchanged incremental QALY gain. Therefore, cost reduction strategies only, such as changing home-based to group sessions, are unlikely to result in the intervention becoming cost-effective unless effectiveness also improves. The 12-month analysis, however, suggested that the intervention may become cost-effective were the effect to be 
sustained beyond the intervention period however this would require a study with longer follow-up beyond 12 months.

\section{Supplementary information}

Supplementary information accompanies this paper at https://doi.org/10. 1186/s12883-020-01852-8.

Additional file 1. Table 1 Unit costs for health-care resource use. Supplementary material 2 - NHS and social care resource use per patient over 6-month. Supplementary material 3 Subgroup (a) and sensitivity (b) analyses results (over six-month).

\section{Abbreviations}

Cl: Confidence interval; QALY: Quality-adjusted life-years; QoL: Quality of life: ICER: Incremental cost-effectiveness ratio; NHS: National Health Service; PSS: Personal Social Service

\section{Acknowledgements}

We acknowledge and thank the participants with Parkinson's; PPI representatives; and member of the Steering and Data Monitoring committees for their valued contributions to the trial. PDSAFE Collaborative Group Members: Professor Ann Ashburn, Dr Kim Chivers Seymour, Professor Helen C Roberts, Professor Ruth Pickering, Professor Sarah E Lamb, Dr Claire Ballinger, Dr Victoria A Goodwin, Professor Lynn Rochester, Professor Alice Nieuwboer, Dr Emma McIntosh Dr Dorit Kunkel, Dr Sophia Hulbert, Ms Carolyn Fitton, Ms Ioanna Marian, Ms Yiqiao Xin, Ms Alison Rowsell and Dr Rachel Summer.

\section{Authors' contributions}

YX conducted the statistical analysis of the cost-effectiveness and drafted the manuscript. AA is the chief investigator of the trial and contributed to study design and interpretation of the present manuscript. RMP contributed to the study design, statistical plan and analysis, editing and interpretation of the present manuscript. KCS is the coordinator of the trial and contributed to the data acquisition. SH is the lead therapist of the PDSAFE intervention in the trial and contributed to the data acquisition of intervention cost. CF is the lead assessor of the trial and contributed to the data acquisition of the resource usage questionnaires. DK contributed to the study design, trial setup and interpretation of the present manuscript. IM managed the study data and contributed to data acquisition and interpretation. HCR, SEL, VAG and $L R$ contributed to the design of the trial and interpretation of the costeffectiveness results. EM designed the trial-based economic evaluation and resource use data collection instruments and supervised the conduct and interpretation of the cost-effectiveness analysis. All authors reviewed and revised the manuscript, and have read and approved the final version.

\section{Funding}

This research was funded by the National Institute for Health Research HTA programme (project number 10/57/21). Dr. Goodwin is supported by the NIHR Collaboration for Leadership in Applied Health Research and Care South West Peninsula. The views and opinions expressed therein are those of the authors and do not necessarily reflect those of the HTA programme, NIHR, NHS or the Department of Health and Social Care. The funders had no role in the design of the study and collection, analysis, and interpretation of data and in writing the manuscript.

\section{Availability of data and materials}

The anonymised datasets used and/or analysed during the current study are available from the corresponding author on reasonable request.

\section{Ethics approval and consent to participate}

Ethics approval for the PDSAFE trial was granted by the NRES South Central Hampshire B Committee (REC reference 14/SC/0039). Written informed consent was obtained from study participants.

\section{Consent for publication}

Not applicable.

\section{Competing interests}

Dr. Goodwin reports grants from National Institute for Health Research, during the conduct of the study. Prof. Lamb reports grants from NIHR Health technology Assessment Programme during the conduct of this study. Prof. Lamb was a member of the HTA Additional Capacity Funding Board, HTA End of Life Care and Add-on Studies, HTA Prioritisation Group, HTA Trauma Board during this study. Prof. McIntosh is a member of the NIHR Public Health Research Funding board. All other authors have nothing to disclose.

\section{Author details}

${ }^{1}$ Health Economics and Health Technology Assessment (HEHTA), Institute of Health \& Wellbeing, University of Glasgow, 1 Lilybank gardens, Glasgow G12 8RZ, UK. ${ }^{2}$ School of Health Science, University of Southampton, Southampton, UK. ${ }^{3}$ Faculty of Medicine, University of Southampton, Southampton, UK. ${ }^{4}$ Centre for Statistics in Medicine, Oxford Clinical Trials Research Unit (OCTRU), University of Oxford, Oxford, UK. ${ }^{5}$ College of Medicine and Health, University of Exeter, Exeter, UK. ${ }^{6}$ Clinical Ageing Research Unit, Institute of Neuroscience, Newcastle University, Newcastle Upon Tyne, UK.

Received: 6 March 2020 Accepted: 1 July 2020

Published online: 11 August 2020

References

1. Partridge N, Scadding J. The James Lind Alliance: patients and clinicians should jointly identify their priorities for clinical trials. Lancet. 2004; 364(9449):1923-4

2. Deane $\mathrm{KHO}$, Flaherty $\mathrm{H}$, Daley DJ, Pascoe R, Penhale B, Clarke CE, et al. Priority setting partnership to identify the top 10 research priorities for the management of Parkinson's disease. BMJ Open. 2014;4:e006434.

3. Kalilani L, Asgharnejad M, Palokangas T, Durgin T. Comparing the incidence of falls/fractures in Parkinson's disease patients in the US population. PLoS One. 2016:11(9):e0161689.

4. Thurman DJ, Stevens JA, Rao JK. Practice parameter: assessing patients in a neurology practice for risk of falls (an evidence-based review): report of the quality standards Subcommittee of the American Academy of neurology. Neurology. 2008;70(6):473-9.

5. Genever RW, Downes TW, Medcalf P. Fracture rates in Parkinson's disease compared with age- and gender-matched controls: a retrospective cohort study. Age Ageing. 2005;34(1):21-4

6. Adkin AL, Frank JS, Jog MS. Fear of falling and postural control in Parkinson's disease. Mov Disord. 2003;18(5):496-502.

7. Bloem BR, Hausdorff JM, Visser JE, Giladi N. Falls and freezing of gait in Parkinson's disease: a review of two interconnected, episodic phenomena. Mov Disord. 2004;19(8):871-84

8. Schrag A, Hovris A, Morley D, Quinn N, Jahanshahi M. Caregiver-burden in parkinson's disease is closely associated with psychiatric symptoms, falls, and disability. Parkinsonism Relat Disord. 2006:12(1):35-41.

9. Weir S, Samnaliev M, Kuo TC, Tierney TS, Walleser Autiero S, Taylor RS, et al. Short- and long-term cost and utilization of health care resources in Parkinson's disease in the UK. Mov Disord. 2018;33(6):974-81.

10. Temlett JA, Thompson PD. Reasons for admission to hospital for Parkinson's disease. Intern Med J. 2006;36(8):524-6.

11. Spottke AE, Reuter M, Machat O, Bornschein B, von Campenhausen S, Berger K, Koehne-Volland R, et al. Cost of illness and its predictors for Parkinson's disease in Germany. PharmacoEconomics. 2005;23(8):817-36.

12. Bloem BR, Steijns JA, Smits-Engelsman BC. An update on falls. Curr Opin Neurol. 2003;16(1):15-26

13. Findley $\sqcup$. The economic impact of Parkinson's disease. Parkinsonism Relat Disord. 2007;13(Suppl):S8-S12.

14. Goodwin VA, Richards SH, Henley W, Ewings P, Taylor AH, Campbell JL. An exercise intervention to prevent falls in people with Parkinson's disease: a pragmatic randomised controlled trial. J Neurol Neurosurg Psychiatry. 2011; 82(11):1232-8.

15. Nieuwboer A, Kwakkel G, Rochester L, Jones D, van Wegen E, Willems AM, et al. Cueing training in the home improves gait-related mobility in Parkinson's disease: the RESCUE trial. J Neurol Neurosurg Psychiatry. 2007; 78(2):134-40.

16. Sherrington C, Whitney JC, Lord SR, Herbert RD, Cumming RG, Close JC. Effective exercise for the prevention of falls: a systematic review and metaanalysis. J Am Geriatr Soc. 2008;56(12):2234-43. 
17. Dibble LE, Addison O, Papa E. The effects of exercise on balance in persons with Parkinson's disease: a systematic review across the disability spectrum. J Neurol Phys Ther. 2009;33(1):14-26.

18. Chivers Seymour K, Pickering R, Rochester L, Roberts HC, Ballinger C, Hulbert $S$, et al. Multicentre, randomised controlled trial of PDSAFE, a physiotherapist-delivered fall prevention programme for people with Parkinson's. J Neurol Neurosurg Psychiatry. 2019;90(7):774.

19. Folstein MF, Folstein SE, McHugh PR. "Mini-mental state". A practical method for grading the cognitive state of patients for the clinician. Psychiatry Res. 1975;12(3):189-98.

20. Hulbert S, Rochester L, Nieuwboer A, Goodwin V, Fitton C, Chivers-Seymour $\mathrm{K}$, et al. Staying safe" - a narrative review of falls prevention in people with Parkinson's - "PDSAFE. Disabil Rehabil. 2019;41(21):2596-605.

21. National Institute for Health and Care Excellence. Guide to the Methods of Technology Appraisal 2013. Available from https://www.nice.org.uk/process/ pmg9/chapter/the-reference-case. Accessed date: 15 Aug 2016.

22. Ramsey SD, Willke RJ, Glick H, Reed SD, Augustovski F, Jonsson B, et al. Cost-effectiveness analysis alongside clinical trials II-an ISPOR good research practices task force report. Value Health. 2015;18(2):161-72.

23. Eurogol Group. EQ-5D-3L | About. Available from https://euroqol.org/eq-5dinstruments/eq-5d-3l-about/. Accessed date: 15 Aug 2016.

24. Faria R, Gomes M, Epstein D, White IR. A guide to handling missing data in cost-effectiveness analysis conducted within randomised controlled trials. PharmacoEconomics. 2014;32(12):1157-70.

25. Ashburn A, Pickering RM, McIntosh E, Hulbert S, Rochester L, Roberts $H$, et al. PDSAFE Trial: A randomised controlled trial of the effectiveness and cost-effectiveness of PDSAFE to prevent falls among people with Parkinson's. Health Technol Assess. 2019;23(36):1-150.

26. Curtis $L \&$ Burns A. Unit costs of health and social care. Personal Social Service Research Unit, University of Kent. 2016. Available from http://www. pssru.ac.uk/. Accessed date: 15 Aug 2016.

27. Department of Health. National Health Service Reference Costs 2015 / 2016. Available from https:/www.gov.uk/government/publications/nhs-referencecosts-2015-to-2016. Accessed date: 22 June 2020

28. EuroQol Group. EuroQol--a new facility for the measurement of healthrelated quality of life. Health Policy. 1990;16(3):199-208.

29. Dolan P. Modeling valuations for EuroQol health states. Med Care. 1997; 35(11):1095-108

30. Drummond M, Sculpher MJ, Claxton K, Stoddart GL, Torrance GW. Methods for the economic evaluation of health care programmes. 4th ed. Oxford: Oxford University Press; 2015.

31. Hoehn MM, Yahr MD. Parkinsonism: onset, progression and mortality. Neurology. 1967;17(5):427-42.

32. Nasreddine ZS, Phillips NA, Bedirian V, Charbonneau S, Whitehead V, Collin et al. The Montreal cognitive assessment, MoCA: a brief screening tool for mild cognitive impairment. J Am Geriatr Soc. 2005;53(4):695-9.

33. Nieuwboer A, Rochester L, Herman T, Vandenberghe W, Emil GE, Thomaes $T$, et al. Reliability of the new freezing of gait questionnaire: agreement between patients with Parkinson's disease and their carers. Gait Posture. 2009:30(4):459-63.

34. Brazier J. Is the EQ-5D fit for purpose in mental health? Br J Psychiatry. 2010; 197(5):348-9.

35. Clarke CE, Patel S, Ives N, Rick CE, Woolley R, Wheatley K, et al. Clinical effectiveness and cost-effectiveness of physiotherapy and occupational therapy versus no therapy in mild to moderate Parkinson's disease: a large pragmatic randomised controlled trial (PD REHAB). Health Technol Assess. 2016:20(63):1-96.

36. Fletcher E, Goodwin VA, Richards SH, Campbell JL, Taylor RS. An exercise intervention to prevent falls in Parkinson's: an economic evaluation. BMC Health Serv Res. 2012;12:426.

37. Farag I, Sherrington C, Hayes A, Canning CG, Lord SR, Close JC, et al. Economic evaluation of a falls prevention exercise program among people with Parkinson's disease. Mov Disord. 2016;31(1):53-61.

\section{Publisher's Note}

Springer Nature remains neutral with regard to jurisdictional claims in published maps and institutional affiliations.

Ready to submit your research? Choose BMC and benefit from:

- fast, convenient online submission

- thorough peer review by experienced researchers in your field

- rapid publication on acceptance

- support for research data, including large and complex data types

- gold Open Access which fosters wider collaboration and increased citations

- maximum visibility for your research: over $100 \mathrm{M}$ website views per year

At BMC, research is always in progress.

Learn more biomedcentral.com/submissions 